\title{
Sartor resartus: el oficio de traducir centones virgilianos ${ }^{1}$
}

\author{
Marcos Carmignani*
}

IDH-CONICET-UNC

\section{Resumen}

El propósito de este artículo es analizar los problemas de traducción que plantean los centones virgilianos, con los que se debe trabajar permanentemente entre dos universos: el del texto base, en nuestra propuesta principalmente la Eneida, y el del nuevo contexto, el universo del mito y del epitalamio. Se examinarán, entonces, algunos pasajes de los centones de Medea, Hippodamia, Alcesta y el Centonuptialis de Ausonio.

\section{Palabras clave}

Centones - Virgilio - Eneida - traducción

\begin{abstract}
The aim of this paper is to study the translation issues posed by Virgilian Centos, with which the translator has to work permanently between two universes: that of the original text, in our proposal mainly the Aeneid, and that of the new context, the universe of myth and epithalamium. Therefore, lines of Medea, Hippodamia, Alcesta and Ausonius' Cento nuptialis will be examined.
\end{abstract}

\section{Keywords}

Centos - Virgil - Aeneid - translation

\footnotetext{
${ }^{1}$ Esta es una versión corregida y ampliada del artículo "El centón de Hippodamia: apuntes de traducción", Stylos 25 (2016), 23-33 y de la ponencia "Sartor resartus: el oficio de traducir los centones virgilianos", leída en el II Simposio Internacional Interdisciplinario Aduanas del Conocimiento, CIECSCONICET, Córdoba, 8, 9 y 10 de abril de 2015.

* Doctor en Letras (UNC). Licenciado en Letras Modernas (UNC) y Licenciado en Letras Clásicas (UNC). Profesor Titular de Filología Latina I y II (UNC). Profesor Adjunto a cargo de Historia de la Literatura Latina I y II (UNC). Investigador Adjunto del CONICET. Tradujo el Cento nuptialis de Ausonio (ver bibliografía) y los centones de Medea, Hippodamia, Alcesta, Europa y Narcissus, que formarán parte de una edición comentada de los centones paganos.
} 
El título de este artículo está tomado de la obra homónima de Thomas Carlyle (1831), cuya trama no tiene nada que ver con los centones, pero su título, El sastre remendado o El sastre rezurcido, describe de manera casi perfecta el oficio de traducir los centones virgilianos: el traductor de este tipo de composiciones trabaja de manera artesanal para verter en su propia lengua un texto cuyo paño es la obra de Virgilio. Mientras el poeta centonario remienda la extraordinaria tela virgiliana que él mismo fragmentó y convirtió en jirones, el traductor, como un sastre, debe rezurcir en su lengua una obra cuyas costuras a veces son toscas, pero cuyo lienzo es, como se sabe, perfecto. Nuestro propósito es, por lo tanto, analizar los problemas de traducción que plantean los centones virgilianos, con los que se debe trabajar permanentemente entre dos universos: el del texto base, en nuestra propuesta principalmente la Eneida, y el del nuevo contexto, el universo del mito y del epitalamio. Se examinarán, entonces, algunos pasajes de los centones de Medea, Hippodamia, Alcesta y el Cento nuptialis de Ausonio.

Antes de comenzar con el análisis, se hace necesario explicar, aunque más no sea brevemente, qué es un centón. El término proviene del griego $\kappa \varepsilon ́ v \tau \rho \omega v-q u e$ originalmente significaba un manto muy humilde, hecho de retazos, que se ponía sobre el lomo de un burro- y alude, en literatura, a un texto poético original formado por versos o partes de versos de poetas célebres, sobre todo de Homero y Virgilio. El origen del género se remonta al mundo griego, por ejemplo, a la parodia a Homero realizada por Hiponacte o Hegemón de Tasos, aunque no forman un continuum de partes homéricas. En el mundo latino, se pueden definir como etapa protocentonaria los textos del Culex, Ciris y Satyricon 132.1, siempre con Virgilio como fuente. Nos han llegado 16 centones virgilianos, desde el 200 hasta cerca del 534. De ellos, 12 son de tipo mitológico o de argumento secular y cuatro contienen material cristiano. Asimismo, 12 se conservan en la llamada Anthologia Latina, una compilación de versos realizada en África, quizá en el siglo VI, que comprende principalmente poetas africanos de la latinidad tardía. El testimonio principal y más antiguo de la Anthologia Latina es el codex Salmasianus, descubierto por el humanista francés Claude Saumaise (15881653), conservado actualmente en París como Parisinus Latinus 10318 y datado entre los siglos VIII y IX. De los cuatro centones que se analizan en este artículo, los tres 
primeros se encuentran en el Salmasianus, mientras que el Cento nuptialis fue transmitido con el resto de las obras de Ausonio 2

Una última aclaración previa al desarrollo del artículo: si todos los centones hubieran sido compuestos con la maestría de Petronio, este artículo no tendría sentido. En la tercera parte del Satyricon, su protagonista Encolpio -convertido por su mitomanía en un epíteto de Odiseo, Polieno- entabla una relación epistolar con una mujer de nombre también odiseico, Circe. Encolpio acuerda lugar y momento de encuentro con Circe, pero poco acostumbrado a las relaciones heterosexuales, sufre una défaillance que lo atormenta. Impotente, recita un brevísimo poema, preso de la ira en contra de su mentula (Sat. 132.11):
Illa solo fixos oculos aversa tenebat,
(Aen. 6.469)
nec magis incepto vultum sermone movetur
(Aen. 6.470)
quam lentae salices | lassove papavera collo.
(Ecl. 5.16, 3.83|Aen. 9.436)

Ella, con la cabeza dada vuelta, tenía fijos los ojos en el suelo, y su rostro no se conmueve con mis palabras más que los flexibles sauces o las amapolas de cuello agotado.

No hace falta ser un experto virgiliano para reconocer detrás de estos versos la mano del mantuano, sobre todo, porque los dos primeros quedan fácilmente en la memoria de todo lector: se trata del encuentro entre Dido y Eneas en el Hades, pasaje de profundo pathos en el que la reina ni siquiera mira al héroe y se refugia en la sombra de Siqueo. El tercer verso, formado por un hemistiquio de las Églogas y otro, notable, del libro 9 de la Eneida -donde se compara el cuello de una amapola, agotado por el peso de la lluvia, con Euríalo, caído en combate, también impregnado de un pathos que el lector difícilmente podría olvidar- cierra este maravilloso ejemplo protocentonario petroniano.

\footnotetext{
${ }^{2}$ La bibliografía sobre los centones es abundante, sobre todo en los últimos 35 años. Estudios generales para introducirse en el mundo centonario son los de Lamacchia (1984), Polara (1990) y Salanitro (1997). Para un completo análisis del codex Salmasianus, cf. Spallone (1982). Entre las ediciones modernas de los centones paganos, se destacan particularmente las de Lamacchia (1981), Salanitro (1981), Paolucci (2006), Salanitro (2009) y Paolucci (2015). Finalmente, una excelente publicación con estudios sobre los textos alojados en la Anthologia Latina (no solo centonarios) es ALRiv. Rivista di Anthologia Latina, dirigida por Loriano Zurli. Para Ausonio, son recomendables la edición de Green (1999) y su comentario (Green 1991).
} 
La intención es la de parodiar irreverentemente la personalidad ridícula de Encolpio, que asimila su mentula a pasajes increíblemente patéticos de la Eneida, como un modo de intelectualizar la realidad baja y prosaica en la que vive. Basta pensar que, en su mitomanía, su miembro difunto es análogo a la reina cartaginesa. Pero el detalle genial que le da sentido a este minicentón y que, en buena medida, lo vuelve el precursor esencial de los centones paródicos (y no sólo), como el de Ausonio, es la sustitución del verso 471 del libro 6 por la combinación ya señalada de Bucólicas y Eneida 9. El genio de Petronio se adelantó al menos un siglo a un modus operandi fundamental de los poetas centonarios, es decir, la utilización silente del contexto original que debe funcionar en la memoria poética del lector: en este caso, ese verso silente, el 471, introducía el segundo término del símil, quam si dura silex aut stet Marpesia cautes. Petronio aprovecha la comparación con la dura roca Marpesia para enfatizar aún más el contraste con la mentula languida de Encolpio y la reemplaza por dos elementos molles, el sauce y la amapola, cuyo cuello cae bajo el peso de la lluvia. Finalmente, un breve comentario sobre la técnica centonaria utilizada en este pasaje del Satyricon, que se adecua a la perfección a la praxis de los poetas centonarios: los dos primeros versos están formados por dos versos completos virgilianos consecutivos, mientras que el segundo está constituido por dos pasajes diferentes de Virgilio (Buc.+Aen.), unidos, como prescribe Ausonio, en uno de los lugares donde caen las cesuras virgilianas (en este caso, la pentemímera). Como decíamos, si todos los centones fueran de esta calidad, el traductor tendría un trabajo más sencillo, ya que Petronio «zurce» el material virgiliano con una perfección admirable ${ }^{3}$. Hosidio Geta es el autor del centón virgiliano más antiguo: se trata de Medea Cento Vergilianus, el más ambicioso de los centones mitológicos y seculares: no solo es el más extenso de este tipo (461 versos) sino que es el único que tiene la forma de una tragedia. En el prólogo (muy similar al de la Medea de Séneca), se leen estos versos (16-18):

exstinctus pudor | atque inmitis rupta tyranni

foedera | et oblitus famae melioris amantis |

\footnotetext{
${ }^{3}$ Quizá el único centón que se iguala en este sentido a Petronio, tanto en irreverencia como en "calidad de zurcido", sea el Cento nuptialis. Petronio, vale la pena mencionarlo, tan solo compuso tres versos centonarios, algo muy diferente a los poemas de largo aliento analizados en este artículo.
} 
oblitusve suae est; | lacrimae volvuntur inanes. |

El pudor desapareció y se rompieron los pactos con el cruel tirano y olvidó la mejor reputación de su amante tanto como la suya propia; mis lágrimas ruedan vacías. ${ }^{4}$

Son palabras de Medea, furiosa con Jasón por las promesas incumplidas. En los vv. 1718, se produce un cambio en el texto: del acusativo plural oblitos de Aen. 4.220-221 oculosque ad moenia torsit / regia et oblitos famae melioris amantis («dirigió sus ojos a las murallas reales y a unos amantes olvidados de mejor fama») se pasa a oblitus, referido a Jasón, en nominativo singular. En el siguiente hemistiquio, oblitusve suae est está tomado de Aen. 3.629 nec talia passus Ulixes / oblitusve sui est Ithacus discrimine tanto («Ulises no soportó tales cosas ni se olvidó de sí mismo el de Ítaca en tan gran peligro») con el cambio al femenino en suae. Obviamente, la ambigüedad de estos versos desconciertan al traductor: con el cambio de oblitos a oblitus, amantis debe ser tomado como genitivo singular y el femenino suae refiere a famae del verso anterior. Las traducciones «olvidado de una reputación mejor para su amante», «olvidado de una amante de mejor fama, se olvidó de su propio buen nombre» $\mathrm{y}$ «olvidado de la fama de una amante mejor, además de su propio buen nombre» - este último con el comparativo melioris apuntando a la comparación entre Medea y la nueva amante de Jasón, Creúsamuestran las diversas posibilidades que permite el texto, pero parece mejor mantener el sentido original de famae melioris de la Eneida («unos amantes olvidados de mejor fama») y traducir: «(Jasón) olvidó la mejor reputación de su amante tanto como la suya propia». Hosidio enfatiza la preocupación de Medea por su reputación, motivo fundamental en las Argonáuticas de Apolonio y en la Medea de Eurípides. Además, el espectador conoce así que Jasón prefiere sus amoríos con Creúsa a su propia fama.

El segundo problema aparece en los vv. 8-9:

quid primum deserta querar? | conubia nostra

reppulit | et sparsos fraterna caede penates. |

\footnotetext{
${ }^{4}$ Todas las citas del centón de Medea corresponden a la edición de Salanitro (1981). Todas las traducciones son nuestras.
} 
¿De qué me lamentaré primero, abandonada como estoy? (Jasón) rechazó nuestro matrimonio y mis penates manchados con la sangre de mi hermano.

El hemistiquio et sparsos fraterna caede penates pertenece a Aen. 4.20-21, cuando Dido admite sus sentimientos frente a Ana: Anna (fatebor enim) miseri post fata Sychaei / coniugis et sparsos fraterna caede penatis ( «Ana (lo confesaré), después del destino de mi desgraciado esposo Siqueo y de que los Penates hayan sido manchados por el crimen de mi hermano»). En este contexto, Dido se refiere al crimen cometido por su hermano Pigmalión en contra de Siqueo, por lo que fraterna es usado en la Eneida como sujeto lógico de la acción, es decir, el crimen cometido por Pigmalión mancha los Penates, mientras que en el centón fraterna se refiere a que Medea mató a su hermano Absirto, es decir, fraterna con sentido objetivo: los Penates manchados por la muerte de Absirto. En este caso, el problema se relaciona con el juego que propone Hosidio a partir de las figuras míticas de Pigmalión y Absirto relacionadas con Dido y Medea, respectivamente. El centonarius aprovecha las diferentes valencias que puede tener el adjetivo fraterna y así cambiar el sentido con respecto al original, algo de lo que el traductor, como intérprete, debe percatarse.

El último ejemplo que mencionaremos de la Medea lo encontramos en los vv. 63-64:

| tibi nomina mille,

mille nocendi artes $\mid$ fecundaque poenis

viscera

Tú tienes mil nombres, mil artes mágicas de hacer daño y unas entrañas fecundas en castigos.

Creonte acusa a Medea de tener unas fecundaque poenis viscera. El contexto original de esta expresión es Aen. 6.598-599, la descripción de Ticio, quien, en el Tártaro, debía soportar que un buitre le royera su hígado que se regeneraba permanentemente: fecundaque poenis viscera, es decir, "sus entrañas regeneradas para el castigo", tomando poenis como dativo incommodi. En el centón, poenis puede ser entendido como ablativo de limitación («tus entrañas son fecundas en tormentos (para los demás) 
»). Pero poenis también puede ser tomado como dativo de finalidad, es decir, «tus entrañas son fértiles para castigar», aludiendo al hecho de que Medea castigará a Jasón con el asesinato de sus propios hijos. La pregunta es obvia: ¿era el centonista consciente de estas ambigüedades? Es inevitable pensar que sí, ya que ejemplos como estos abundan en los mejores centones, donde sus autores aprovechaban el juego entre el contexto original y el nuevo marco para que el lector pudiera apreciar su habilidad compositiva. Sin embargo, este tipo de ambigüedades es imposible de verter en la traducción y obliga al traductor a pensar y repensar diferentes modalidades con las que resolver el problema. Volveremos sobre esto más adelante.

El segundo centón que analizaremos es Hippodamia, un poema de 162 versos, de autor anónimo, que cuenta la historia de la hija de Enómao, que, con la ayuda del auriga Mirtilo, obtiene la victoria sobre su padre y se casa con Pélope. Mirtilo, engañado por las promesas de la virgen, traicionado y traidor, se arroja al mar, que tomará su nombre. El autor cuenta este relato principalmente con versos y partes de versos tomados de la Eneida, evidentemente porque ofrece un material más rico para la reescritura de un mito como es el de Hipodamía, donde el engaño y la tragedia son elementos esenciales. Desde el mismo proemio del centón comienzan a aparecer dificultades para la traducción (vv. 1-7):

Pandite nunc Helicona, deae, | nunc pectore firmo |

este duces, o si qua via est, | et pronuba Iuno; |

pallida Tisiphone, | fecundum concute pectus! |

Non hic Atridae | nec scelus exitiale Lacaenae: |

hic crudelis amor. | Nunc illas promite vires, |

maius opus moveo: | quaesitas sanguine dotes |

et scelerum poenas | inconcessosque hymenaeos.

¡Abran ahora el Helicón, oh diosas, ahora con pecho firme sean las guías, si fuera posible también tú, oh Juno, protectora del matrimonio; y tú, pálida Tisífone, golpea tu pecho fecundo! Aquí [no se cantan] los Atridas ni el crimen funesto de la Espartana: aquí [se canta] el cruel amor. Saquen ahora esas fuerzas 
[inspiradoras], empiezo una obra más grande: dotes buscadas con sangre y castigos de crímenes y bodas prohibidas 5 .

El contexto original del segundo hemistiquio (nunc pectore firmo) es Aen. 6.260-261: tuque invade viam vaginaque eripe ferrum/ nunc animis opus, Aenea, nunc pectore firmo («y tú encamínate y saca la espada de la vaina: ahora hace falta coraje, Eneas, ahora el pecho firme»). Son palabras de la Sibila a Eneas antes de entrar al Hades, para que el héroe no tema ante las figuras que irán apareciendo. Sin embargo, en el centón, la expresión nunc pectore firmo / este duces ${ }^{6}$ asocia a las Musas con un espíritu guerrero que estas no necesitan, porque lo único que el poeta les pide es ayuda para recordar. El «pecho firme» de las Musas, en este sentido, suena algo descolocado. Quizá una opción sea traducir «con decisión» ${ }^{7}$.

El problema más importante para la traducción de este proemio son los versos Non hic Atridae | nec scelus exitiale Lacaenae: | hic crudelis amor. No solo la omisión de un verbo del tipo canere o dicere es notable en un proemio, sino también el hecho de que los sintagmas nominales están en nominativo, presuponiendo un uso muy extraño del verbo omitido, ya que tanto cano como dico en los proemios siempre rigen objeto directo $^{8}$.

El segundo hemistiquio del v. 5, tomado de Aen. 5.191, también implica sobreentender algún concepto relacionado con el proemio para traducir correctamente, porque Nunc illas promite vires es demasiado genérico como para entender a qué se refiere la fuerza, más todavía si recordamos el pasaje de donde proviene:

\footnotetext{
${ }^{5}$ Todas las citas del centón de Hippodamia corresponden a la edición de Paolucci (2006). Todas las traducciones son nuestras.

${ }^{6}$ este duces, o si qua via est son las palabras de Eneas dirigidas a las palomas de Venus, enviadas por la diosa como augurium oblativum antes del ingreso del héroe al Hades.

${ }^{7}$ A pesar de esto, es notable cómo el centonista logró en el v. 3 pallida Tisiphone, | fecundum concute pectus! relacionar a Tisífone con Alecto, tal como se lee en Eneida 7:

fecundum concute pectus,

dissice compositam pacem, sere crimina belli;

arma velit poscatque simul rapiatque iuventus (Aen. 7.338-340)

Golpea tu pecho fecundo, desarma la paz acordada, siembra recriminaciones para la guerra; que la juventud quiera las armas y al mismo tiempo las pida y las arrebaten.

8 Algunos ejemplos célebres: a) con cano: Sicelides Musae, paulo maiora canamus (Ecl. 4.1); arma virumque cano, (Aen. 1.1); Motibus astrorum nunc quae sit causa canamus (Lucr. 5.510); b) con dicere: In nova fert animus mutatas dicere formas / corpora (Ov., Met. 1.1-2).
} 
hortatur Mnestheus: 'nunc, nunc insurgite remis,

Hectorei socii, Troiae quos sorte suprema

delegi comites; nunc illas promite viris, (Aen. 5.189-191)

Mnesteo los exhorta: “ahora, ahora levántense sobre los remos, compañeros de Héctor, a quienes elegí como acompañantes en el último destino de Troya; ahora saquen esas fuerzas".

En el contexto del centón, esas fuerzas deben ser las inspiradoras del canto.

Ya en la primera sección narrativa de la Hippodamia, en el v. 14 se lee: tormenti genus | incertum de patre ferebat («soportaba como padre un tipo incierto de tormento»). Este verso trata de la condición de Enómao, quien como padre, mataba a los pretendientes de su hija porque un oráculo había establecido que sería asesinado por su yerno. El verso en cuestión es el resultado de la unión de dos hemistiquios: Aen. 8.487 tormenti genus et sanie taboque fluentis y de Aen. 11.341 nobilitas dabat, incertum de patre ferebat. El contexto del primero es el siguiente (Aen. 8.485-488):

mortua quin etiam iungebat corpora uiuis

componens manibusque manus atque oribus ora,

tormenti genus, et sanie taboque fluentis

complexu in misero longa sic morte necabat.

Es más: unía los cadáveres con los vivos, juntando manos con manos y bocas con bocas, espantosa tortura, y empapados en pus y sangre podrida los mataba así con larga agonía y en horrible abrazo.

El del segundo (Aen. 11.340-341):

seditione potens (genus huic materna superbum

nobilitas dabat, incertum de patre ferebat)

poderoso en la desunión (la nobleza materna le daba un linaje soberbio, innoble el que provenía de su padre). 
La expresión tormenti genus tiene función apositiva respecto de la descripción del suplicio que Mecencio daba a sus enemigos; en cambio, en el centón, cumple función de objeto directo de ferebat, que a su vez sufre un cambio semántico porque en el centón significa «soportar», mientras que en Virgilio, unido al complemento de origen de patre quiere decir «derivar, proceder». En el centón, por lo tanto, hay que entender de patre con una función lógica diferente, es decir, como el sentido de un complemento de argumento: «acerca de su condición de padre». Además, incertum concuerda en ambos textos con el sustantivo genus, que en Eneida 8 y en el centón significa «tipo», mientras que en Eneida 11 quiere decir «estirpe»; sin embargo, incertum en la Eneida no puede significar otra cosa que «innoble», mientras en el centón significa «impreciso».

El último ejemplo de Hippodamia que analizaremos son los vv. 36-37:

Tempore iam ex illo | nil magnae laudis egentes

deponunt animos, | scelerata excedere terra. |

Ya desde aquel tiempo, [los jóvenes] no necesitados de gran gloria deponen sus ánimos, abandonan la tierra maldita.

El problema principal del verso es que se hace necesaria la interpunctio después de animos para no entender, como hacen Riese y Baehrens ${ }^{9}$, que los jóvenes pretendientes «deponen sus ansias de alejarse de la tierra funesta», algo que es improbable dado el contexto, que justamente parece decir lo contrario, puesto que la ciudad de Pisa los esperaba para un fin macabro. Se debe, por lo tanto, eliminar cualquier posible relación entre excedere y animos, que había sido introducida por la parataxis de Aen. 3: Omnibus idem animus, scelerata excedere terra («Todos tenían el mismo ánimo: salir de una tierra maldita»). Por esto, el traductor puede confundirse e interpretar el infinitivo excedere con el mismo valor que en Eneida, es decir, con sentido descriptivo-narrativo, en lugar del valor epexegético que tiene en el centón.

\footnotetext{
${ }^{9}$ A. Baehrens, Poetae Latini minores, Lipsiae, 1882; A. Riese, Anthologia Latina, editio altera, Lipsiae, 1894-1906.
} 
Alcesta es un centón que comparte con Hippodamia dos rasgos que hicieron que algunos críticos los consideraran de un mismo autor: tiene 162 versos y es de autor anónimo. A pesar de estas coincidencias, Paolucci (2015: lxxx, n. 312) sugiere que ambos centones no son de la misma mano pero sí probablemente de la misma escuela. Alcesta narra el mito de Alcestis y Admeto, ya tratado en la famosa tragedia de Eurípides. En el proemio del centón encontramos problemas para traducir, puesto que el poema comienza con este anuncio del poeta $(\mathrm{vv} .1-2)^{10}$ :

Egregium forma iuvenem | pactosque hymenaeos |

incipiam

Comenzaré [la historia] del joven (Admeto) de belleza extraordinaria y de los pactos de boda.

Como se ve, el verbo incipere tiene un régimen inusual, nunca utilizado por Virgilio: en la Eneida nunca aparece dicho verbo con elisión absoluta del infinitivo objeto, en este caso «cantar», «narrar», que a su vez regiría los objetos iuvenem y pactosque hymenaeos. Virgilio presenta dos usos del verbo: a) con infinitivo objeto, como ocurre en Aen. 4.76 incipit effari mediaque in voce resistit («comienza a hablar y se detiene en medio del discurso») o en 4.160-161 Interea magno misceri murmure caelum / incipit («Mientras tanto, el cielo comienza a llenarse de un gran murmullo») y b) en sentido absoluto, sobreentendiendo un verbum dicendi pero cuyo objeto no está presente (como en el centón) sino que es el discurso directo, como ocurre en el caso del modelo centonario: quamquam animus meminisse horret luctuque refugit, / incipiam. (Aen. 2.12-13) («aunque el ánimo se eriza al recordar y huye del llanto, comenzaré»). El centón, por lo tanto, innova en un uso del verbo que sobreentiende elementos inéditos en Virgilio y raros en la tradición literaria latina, de modo que verdaderamente el zurcido se hace evidente.

En los vv. 8-10 encontramos otro caso aún más grave que el anterior en donde la tarea del traductor debe ser la de un sastre habilidoso:

\footnotetext{
10 Todas las citas del centón de Alcesta corresponden a la edición de Paolucci (2015). Todas las traducciones son nuestras.
} 
Iura dabat legesque viris: | sub rupe leonem |

aut spumantis apri cursum | qui foedere certo

et premere et laxas sciret dare iussus habenas. |

[Pelias] daba órdenes y leyes a los pretendientes: [si había] quien supiera, establecido un pacto, domar un león entre las rocas o encerrar el camino de un jabalí espumeante y sujetar o aflojar las riendas según sea la orden.

Se trata de las pruebas que Pelias exigía que superara el futuro cónyuge. El primer detalle es la falta de concordancia entre el pronombre relativo qui (singular) y su antecedente (viris, plural). En el original virgiliano (Aen. 1.62-63), la construcción es gramatical, con qui en concordancia con regem: regemque dedit, qui foedere certo / et premere et laxas sciret dare iussus habenas («les dio un rey que, con ley segura, bajo sus órdenes supiera sujetar o aflojar las riendas»). El segundo elemento es la expresión foedere certo que en el original alude a la «ley» de Eolo, que debe cuidar los vientos en su cueva, mientras que en el centón foedus puede asumir el sentido de «mano»o «decisión» («con mano cierta»), tal como entiende Salanitro (2007: ad loc.), una acepción bastante alejada del sentido del término, o, mejor, como piensa Paolucci (2015: ad loc.), con el significado de «tratado, pacto, alianza, unión, acuerdo, ley, vínculo», referido a las condiciones establecidas por Pelias. Pero, evidentemente, a pesar de la solución de Paolucci, el texto es bastante oscuro en este punto.

Un tercer aspecto del pasaje se relaciona con la expresión sub rupe leonem / aut spumantis apri cursum vinculada con et premere et laxas sciret dare iussus habenas. La frase parece no tener sentido si se la toma tal como aparece en el texto: «que bajo sus órdenes supiera sujetar o aflojar las riendas, al león bajo la roca o el camino del jabalí espumeante». Los verbos premere y dare no parecen regir los acusativos leonem y cursum, sino, tal como su contexto original lo muestra, a habenas. Una posibilidad es que tanto leonem como cursum dependan, en apo koinú, de premere, de modo que el sentido fuera, en el primer caso, «supiera domar un león bajo la roca» (cf. Aen. 9.330: tris iuxta famulos temere inter tela iacentis / armigerumque Remi premit, «mata a su lado a tres sirvientes que yacían tranquilos entre sus armas y al escudero de Remo»). El caso de cursum, aunque ciertamente en apo koinú, es más sencillo porque el pasaje original virgiliano (Aen. 1.324) incluye el mismo verbo: aut spumantis apri cursum 
clamore prementem, «apurando a gritos la carrera de un jabalí espumeante». Como puede verse, nuevamente las costuras del zurcido son evidentes.

El último centón que analizaremos es también el más logrado de los centones paganos. Se trata del Cento nuptialis, obra de Décimo Magno Ausonio, el más conocido de los poetas doctos de la segunda mitad del siglo IV. Este centón conmemora las bodas de Graciano y Constancia, matrimonio que se realizó en 374, pero el centón probablemente fue escrito después, por orden de Valentiniano I. Las fechas de composición se sitúan entre 375 (muerte del emperador) y 394 (muerte de Ausonio). El poema tiene 131 hexámetros divididos en ocho secciones. Entre las secciones 7 y 8 hay una parte titulada Parecbasis, escrita en prosa.

En la sección titulada Cena nuptialis («Cena nupcial»), se lee en los vv. 22-24:

postquam exempta fames et amore compressus edendi, |

crateras magnos statuunt | Bacchumque ministrant. |

sacra canunt, | plaudunt choreas et carmina dicunt. |

Después de haber saciado el hambre y satisfecho el deseo de comer, disponen grandes cráteras. Sirven vino. Cantan himnos, bailan en coros y entonan versos ${ }^{11}$.

El verbo plaudo significa en general «aplaudir, golpear», por lo que en este verso centonario tiene poco sentido con su objeto choreas, «baile, baile en círculos». El traductor debe ser consciente de que necesariamente debe recurrir al original virgiliano en numerosas oportunidades para dar sentido al nuevo texto. Así, leemos en Aen. 6.644 pars pedibus plaudunt choreas et carmina dicunt, "otra parte [de las almas en los Campos Elíseos] bailan en círculo batiendo los pies y entonan versos», lo que resuelve el problema de la elisión de pedibus, elemento fundamental para que el verbo plaudo tenga el sentido de «bailar».

En la sección Descriptio Egredientis Sponsae («Descripción de la salida de la esposa»), se lee (vv. 38-40):

\footnotetext{
11 Todas las citas del Cento nuptialis corresponden a la edición de Green (1999), mientras que las traducciones pertenecen a la edición de La Fico Guzzo, Carmignani (2012).
} 
illam omnis tectis agrisque effusa iuventus

turbaque miratur matrum. | vestigia primi

alba pedis, | dederatque comam diffundere ventis. |

Toda la juventud, esparcida por las casas y los campos, y una multitud de matronas se maravillan ante ella. Dando el primer paso con su pie blanco, había dejado su cabellera suelta a los vientos.

El pasaje es de difícil traducción principalmente por dos motivos: a) sintáctico y b) semántico. En el primer caso, el texto original virgiliano remite a Aen. 5.566-567, donde se describe un caballo tracio con manchas y frente blancas: portat equus bicolor maculis, vestigia primi / alba pedis frontemque ostentans arduus albam («lo lleva un caballo bicolor, con manchas blancas, mostrando, altivo, las huellas blancas de su pata delantera y su frente blanca»). La ausencia en el centón del participio ostentans, que rige el objeto directo vestigia alba complica las cosas a la hora de traducir. Este tipo de elisiones es muy habitual en los centones, ya que el contexto ayuda -no siempre, pero frecuentemente- a llenar de sentido el pasaje. El motivo semántico complica aún más la traducción. La «pata delantera» del caballo (primi pedis) es la pata que marca el ritmo de marcha, lo que no sería extraño si no estuviera aplicado a la novia, que, entonces, queda asociada con un caballo. La parodia y la comicidad son evidentes, pero no debe perderse de vista que la novia llevaba zapatos de un color entre amarillo y naranja, lo que tanto Catulo (61.160, aureolos pedes, «pie dorado») como Ausonio tratan de describir.

El segundo pasaje ausoniano pertenece a la sección Ingressus in cubiculum («Ingreso en la habitación»), donde los novios comienzan el acercamiento sexual (vv. 80-82):

postquam est in thalami pendentia pumice tecta

perventum, | licito tandem sermone fruuntur. |

congressi iungunt dextras | stratisque reponunt. |

Después que entraron en la cámara nupcial, con su techo de piedra pómez, finalmente gozan de una placentera conversación. Acercándose, unen sus diestras y se recuestan sobre el lecho. 
El principal problema de este pasaje es sintáctico. En el v. 82, reponunt (verbo transitivo) no tiene objeto. Con la traducción intentamos recuperar el sentido a partir de stratisque, pero el contexto original (Aen. 4.391-392) es el de Dido en un estado de colapso ante la noticia, por boca del propio Eneas, de la partida del héroe: suspiciunt famulae conlapsa membra / marmoreo referunt thalamo stratisque reponunt («la sostienen sus sirvientas y llevan sus miembros desfallecientes al tálamo de mármol y la recuestan en el lecho»). Green (1991: ad loc.) piensa que puede haber una laguna y que Ausonio escribió el resto del verso 8.467, es decir, congressi iungunt dextras mediisque residunt («acercándose, unen sus diestras y se sientan en el medio del palacio [el verso 8.468 tiene aedibus] »), que un escriba puede haber confundido con stratisque reponunt. Más allá de esta posibilidad, el texto muestra una dificultad sintáctica que debe ser resuelta en la traducción.

El último caso del Cento nuptialis corresponde a su sección más famosa, la Imminutio, una de las más detalladas descripciones del coito en la literatura latina. En este artículo analizaremos los últimos versos de esta sección, con la intención de mostrar no ya problemas que tienen que ver con el zurcido, sino con otra problemática que debe enfrentar el traductor en los mejores centones: la polisemia. En los vv. 129-131 se describe el clímax sexual de la pareja:

tum creber anhelitus artus

aridaque ora quatit, sudor fluit undique rivis, |

labitur exanguis, | destillat ab inguine virus. |

entonces, un jadeo repetido golpea sus miembros y sus bocas resecas, el sudor fluye por todas partes en torrentes, él se deja caer exangüe, el semen gotea de su verga.

Es un final que deja al lector sorprendido, por la vivacidad de la escena compuesta -no olvidarlo- con versos virgilianos. Nos detendremos en el último hemistiquio, tomado de Georg. 3.281. En ese pasaje, Virgilio alude al hipómanes, «humor que se desprende de la vulva de la yegua cuando está en celo» (cf. DRAE, s.v.), lo que claramente no tiene que ver con el semen, pero si buscamos el término virus en el diccionario la acepción de «fluido seminal del macho» aparece recién en la Historia Natural de Plinio, hecho que 
debe hacer recapacitar al traductor no ya de los centones sino de los textos tardoantiguos: es absolutamente necesario tener en cuenta la diacronía de la lengua latina para realizar una traducción lo más correcta posible y no quedarse estancado, como ocurrió con los editores de la Anthologia Latina hasta el siglo XIX, en un latín clásico. En este caso, Ausonio utiliza el término virus porque ya en su época era una de las formas para decir «semen», algo que en tiempos de Virgilio no ocurría. Por otra parte, destillo significa «gotear», pero en el lenguaje obsceno de las inscripciones (CIL $4.760)^{12}$ el sust. destillatio significa con toda seguridad nuestro término vulgar «acabada» («corrida» en español peninsular), de modo que la combinación de virus destillat no puede referir a otra cosa que a la eyaculación, a pesar de que el contexto virgiliano dista mucho de esto. El centón, entonces, implica una polisemia que abarca no solo la diacronía literaria sino también diversos registros lingüísticos, como el vulgar de las inscripciones.

Como conclusión, los principales problemas relacionados con la traducción de los centones se vinculan con las incongruencias lógicas y las alteraciones semánticas de ciertas palabras al pasar del original virgiliano al nuevo texto. Es lícito, por lo tanto, en este contexto centonario, hablar de «costuras», es decir, las uniones entre hemistiquios y versos virgilianos transportados al centón que el poeta en algunos casos no logró «zurcir» de manera impecable. Esta unión imperfecta genera, a la hora de traducir, ciertas complicaciones que ponen a prueba no solo la destreza del traductor sino también lo obligan a tomar partido definitivamente por una opción entre estas dos: traducir el texto tal como lo recibimos de la tradición manuscrita, dejando a la vista sus «costuras», o traducir el texto resolviendo esos problemas al incluir algún tipo de elemento esclarecedor de la frase. Nuestra postura se inclina por la segunda posibilidad, porque, más allá de los defectos en el texto latino «zurcido», es necesario que una traducción sea comprensible para aquel que desconoce el latín y que no tiene la posibilidad de percibir las «costuras» del original.

Con respecto a las ambigüedades y a la polisemia que implica el texto centonario, en los mejores centones (como los casos de Petronio y Ausonio analizados) se trata de una

\footnotetext{
${ }^{12}$ oblige mea, fela . . mentlam elinges . . . destillatio me tenet, "lamémela toda, chupala de punta a punta, ¡ya termino!".
} 
ambigüedad deliberada que enriquece el texto: el lector, al percatarse de la polisemia, puede ver más allá de la superficie textual, profundizando el sentido e insertándose en el espléndido mecanismo de la imitatio. Cuando la ambigüedad no es intencional, los problemas traductivos se multiplican: es ahí cuando debe aparecer la pericia del traductor, quien debe convertirse en un verdadero sartor, un «sastre remendón», para rezurcir en su propia lengua las costuras, a veces burdas, de los centones virgilianos.

\section{Bibliografía}

Green, R .P. H. (1991). The Works of Ausonius. Oxford: Oxford University Press.

Green, R. P. H. (1999). Decimi Magni Ausonii Opera. Oxford: Oxford University Press.

La Fico Guzzo, M. L., Carmignani, M. (2012). Proba Cento Vergilianus De Laudibus Christi. Ausonius. Cento Nuptialis. Introducción, traducción y notas, Bahía Blanca: EDIUNS.

Lamacchia, R. (1981). Hosidius Geta. Medea. Cento Vergilianus. Leipzig: Teubner (1984). Centones. En Enciclopedia Vergiliana, Vol I, Roma: Istituto dell'Enciclopedia Vergiliana.

McGill, S. (2005). Virgil Recomposed. The Mythological and Secular Centos in Antiquity, Oxford: Oxford University Press.

Mynors, R. (1969). Virgilii Maronis Opera. Oxford: Oxford University Press.

Paolucci, P. (2006). Il centone virgiliano Hippodamia dell'Anthologia Latina. Introduzione, edizione critica, traduzione e commento, Hildesheim-Zürich-New York: Olms.

(2015). Il centone virgiliano Alcesta dell'Anthologia Latina. Introduzione, edizione critica, traduzione e commento, Hildesheim-Zürich-New York: Olms.

Polara, G. (1990). I centoni. En Cavallo, G., Fedeli, P., Giardina, A. (edd.), Lo spazio letterario di Roma antica, vol. III. Roma: Salerno Editrice.

Salanitro, G. (1981). Osidio Geta: Medea. Introduzione, testo critico, traduzione e indici. Con un profilo della poesia centonaria greco-latina, Roma: Ateneo. 
(2007). Alcesta. Cento Vergilianus. Acireale-Roma: Bonnano Editore.

(2009). Silloge dei Vergiliocentones minori. Introduzione, testo critico, traduzione e note, Acireale-Roma: Bonnano Editore.

Spallone, M. (1982). Par. Lat. 10318 (Salmasiano): dal manoscritto altomedievale ad una raccolta enciclopedica tardoantica. En Italia medioevale e umanistica. 25, 1-71. 